HEDL-7532

\title{
EFFECTS OF TENSILE AND COMPRESSIVE STRESSES ON IRRADIATION-INDUCED SWELLING IN AISI 316
}

\author{
HEDL- -7532
}

DE85 014009 
Operated by

Westinghouse

Hanford Company

A Subsidiary of

for the U.S. DOE

Westinghouse Electric

Corporation

Contract No.

P.D. Box 1970

DE-ACO6-76FF02170

Richland, WA 99352

Hanford Engineering Development Laboratory

INFORMATION CONCERNING USE OF THIS DOCUMENT

NOTICE

This report was prepared as an account of work sponsored by an agency of the United States Government. Neither the United States Government nor any agency thereof, nor any of their employes, nor any of their contractors, subcontractors or their employes, makes any warranty, express or implied, or assumes any legal liability or responsibility for the accuracy, completeness, or any third party's use or the result of such use of any information, apparatus, product, or process disclosed, of represents that its use would not infringe privately owned rights. Reference herein to any specific commercial product, process, or service by trade name, trademark, manufacturer, or otherwise, does not necessarily constitute or imply its endorsement, recommendation, or favoring by the United States Government or any agency thereof or its contractors or subcontractors. 
HEDL-7532

\title{
EFFECTS OF TENSILE AND COMPRESSIVE STRESSES ON IRRADIATION-INDUCED SWELLING IN AISI 316
}

\author{
T. Lauritzen (GE) \\ W.L. Bell (GE) \\ G.M. Konze (GE) \\ J.M. Rosa (GE) \\ S. Vaidyanathan (GE) \\ F.A. Garner (HEDL)

\section{DISCLAIMER}

This report was prepared as an account of work sponsored by an agency of the United States Government. Neither the United States Government nor any agency thereof, nor any of their employees, makes any warranty, express or implied, or assumes any legal liability or responsibility for the accuracy, completeness, or usefulness of any information, apparatus, product, or process disclosed, or represents that its use would not infringe privately owned rights. Reference herein to any specific commercial product, process, or service by trade name, trademark, manufacturer, or otherwise does not necessarily constitute or imply its endorsement, recommendation, or favoring by the United States Government or any agency thereof. The views and opinions of authors expressed herein do not necessarly state or reflect those of the United States Government or any agency thereof. 
EFFECTS OF TENSILE AND COMPRESSIVE STRESSES ON IRRADIATION-INDUCED SWELLING IN AISI 316

T. Lauritzen, W. L. Bell, G. M. Konze, J. M. Rosa and S. Vaidyanathan (General Electric Company)

F. A. Garner (Hanford Engineering Development Laboratory)

\section{$1.0 \quad$ Objective}

The object of this effort is to identify the effects of applied external or internal stresses on radiation-induced dimensional changes in metals and to predict the impact of these effects on fusion reactor design and performance.

\section{$2.0 \quad$ Summary}

The results of two recent experiments indicate that the current perception of stress-affected swelling needs revision. It appears that compressive stresses do not delay swelling as previously modeled but actually accelerate swelling at a rate comparable to that induced by tensile stresses.

\subsection{Program}

Title: Irradiation Effects Analysis (AKJ)

Principal Investigator: D. G. Doran

Affiliation: Hanford Engineering Development Laboratory

\subsection{Relevant DAFS Program Plan Task/Subtask}

Task II.C.2.1 Effects of Material Parameters on Microstructure

Task II.C.16 Composite Correlation Models and Experiments

5.0 Accomplishments and Status

5.1 Preface

This report is divided into two parts. The first summarizes earlier experimental and modeling efforts directed toward describing stress-affected swelling. It also describes the conclusions of two recent independent studies which contradict one major facet of the current stress-affected swelling model. The second part describes work by Lauritzen and coworkers at General Electric Company done under the sponsorship of the U.S. Breeder Reactor program; it is published here with the permission of that program.

\section{$5.2 \quad$ Part I}

In an earlier report (1) it was shown that many alloys exhibit an enhancement of irradiation-induced void swelling due to the application of biaxial tensile stresses during irradiation. For AISI 316 this enhancement was shown to arise from a shortening of the incubation period of void growth. No effect of stress was seen on the steady-state swelling rate. A correlation developed to describe this phenomenon is currently employed in the U.S. Breeder Reactor Program. (1) 
Before this correlation can be employed in fusion reactor design studies, one must consider the impact of the differences in the two reactor environments and also make an assessment on how best to extrapolate the data into untested stress states. It is important to note that the total data base was developed from essentially isothermal irradiations of the walls of thin tubes subjected to a constant biaxial tensile stress. There were no previously published data on the effect of compressive or torsional stress states and no experiments which provided guidance on how to incorporate the effects of stress history. These considerations are potentialiy quite important for three reasons. First, the stresses anticipated in the first wall of Tokamak-type reactors will be time-dependent, cycling from tensile to compressive, and will not develop gradually like the fission gas loading typical of breeder reactor fuel pins. Second, there is some unpublished evidence which indicates that the current model (based only on microstructural concepts) incorrectly predicts that compressive stresses will delay swelling. These new data indicate that perhaps compressive or torsional stresses also accelerate swelling, particularly at higher temperatures. Third, the duration of the void incubation period of AISI 316 steel has been shown to be primarily determined by the microchemical evolution of the matrix, a process which is normally rather sluggish compared to the microstructural evolution. (2) The greatest sensitivities of the microchemical evolution appear to be associated with variations in flux, temperature and stress, all three of which will undergo pronounced simultaneous variations in the walls of pulsed reactors. The possible synergisms for such complex and sensitive histories may lead to substantial changes in the rate of the microchemical evolution. Additional data presented in later reports indicated that applied tensile stresses indeed accelerate the microchemical evolution at temperatures above $550^{\circ} \mathrm{C}$ by accelerating the formation of stress-sensitive intermetalific phases. (3-5)

A subsequent modelling effort of the effect of stress on phase formation indicated that the phases formed in AISI 316 would be sensitive only to the hydrostatic component and not the deviatoric component of the stress state. (6) Therefore one would expect that compressive stresses would delay intermetallic phase formation and thereby temporarily suppress swelling. There was some discomfort with this conclusion, however, since all data were derived in a tensile-shear environment and no data on deviatoric or compressivehydrostatic conditions were available to confirm such a prediction.

Other experimenters were therefore encouraged to generate data for compressive stress environments. Kera and coworkers had earlier used $6 \mathrm{MeV}$ deuteron bombardment at $550^{\circ} \mathrm{C}$ and demonstrated that tensile stresses accelerate void nucleation and shorten the duration of the transient regime in a $\mathrm{Fe}-\mathrm{Cr}-\mathrm{Ni}-\mathrm{Mo}_{\mathrm{O}}$ quaternary alloy representative of the base composition of AISI 316.(7) They have recently extended this study using $7 \mathrm{MeV}$ protons and both compressive and tensile stresses of $100 \mathrm{MPa}$ at $500^{\circ} \mathrm{C}$. $(8)^{\circ}$ They conclude that the irradiation creep rate is unaffected by the sign of the stress, a conclusion that might well be expected. They also find, however, that the swelling is accelerated equally by tensile and compressive stresses.

In another recent study, Lauritzen and coworkers examined the swelling across a bent beam specimen of $20 \%$ cold-worked AISI 316 strained in a four-point bending mode during fast neutron irradiation in EBR-II at $400-425^{\circ} \mathrm{C} .(9)$ They found that void nucleation and swelling at $\sim 40 \mathrm{dpa}$ were accelerated equally on both the tensile and compressive sides of the beam when compared to the region of the beam encompassing the neutral stress axis. Lauritzen and coworkers have now extended this study to higher neutron fluence. This work is described in the next section.

\section{$5.3 \quad$ Part II}

\subsubsection{Introduction}

In a recent publication, (9) we presented experimental evidence that irradiation-induced swelling in AISI 316 is increased by an applied bending stress at irradiation temperatures representative of operating LMFBR fuel assembly ducts. The results further indicated that the observed swelling enhancement was due to an accelerated nucleation of voids in both tension and compression regions of bent beams relative to that of a zero stress region at the beam centerline. However, because the specimens examined in that study accumulated a moderately low fluence $\left(8 \times 10^{22} \mathrm{n} / \mathrm{cm}^{2}, E>0.1 \mathrm{MeV}\right)$, the swelling was rather small with correspondingly large uncertainties. Moreover, it was assumed, based on the current swelling data and design equations, that the swelling represented by this fluence level was still well within the incubation regime. As a result of the interest that these data generated and the implications of stress-enhanced swelling on core structural materials, the experimental and analytical program was extended to evaluate sibling specimens of AISI 316 which had been reconstituted for additional irradiation. 
In the present work, three beams ranging in fluence from 11.2 to $14.9 \times 10^{22} \mathrm{n} / \mathrm{cm}^{2}$ were selected for examination. The results of those examinations along with summaries of the previous low-fluence data are presented below.

\subsubsection{Description of Material}

The 20 percent cold-worked 316 specimens examined in this program were prepared as 0.030 -inch thick coupons from wrought stock of Carpenter Heat No. K81581. The specimens were irradiated as uniform beam creep specimens in the $\mathrm{Cl}$ irradiation creep experiment, details of which have been given in numerous progress reports. (See, for example, Reference 10 and the bibliography appended thereto.) The multiple-element specimen train used in this experiment was designed to permit the removal of the entire train, fully encapsulated in a sodium-filled duct, from the irradiation capsule at various irradiation intervals for nondestructive examination of the weighted beams. by neutron radiography. At the completion of one of these examination periods (after the fifth interim examination and the accumulation of a peak fluence of roughly $8 \times 10^{22} \mathrm{n} / \mathrm{cm}^{2}, E>0.1 \mathrm{MeV}$ ), it was discovered that the 22 -element train had extended to such a

degree that further irradiation would have caused the deadweight loading the train to bottom-out at the base of the capsule. Since the train was arranged into four modules of five to seven elements per module, it was decided to remove the lower two modules from the train, reattach the deadweight to the upper modules and resume the irradiation. Having done this, the lower modules were available for destructive examination and subsequently provided beams 13 and 15 for the first swelling examination. The remaining two modules, containing a total of twelve beams, accumulated an additional peak fluence of $7 \times 10^{22}$ $\mathrm{n} / \mathrm{cm}^{2}$ before the experiment was terminated at $15 \times 10^{22} \mathrm{n} / \mathrm{cm}^{2}$.

The three reconstituted beams selected for swelling examination included the highest fluence beam, the highest temperature beam and the beam estimated from the current swelling design equation to have undergone the largest swelling. These beams were numbered 12,6 and 8 , respectively. Their irradiation and stress-strain histories are given, along with data from the previously reported two beams, in Table 1.

\section{TABLE 1}

Irradiation Parameters and Loading/Strain Conditions of the LUB/LUM Uniform Beam Specimens Selected for TEM Examination

\begin{tabular}{|c|c|c|c|c|c|c|c|}
\hline $\begin{array}{l}\text { Beam } \\
\text { No. }\end{array}$ & $\begin{array}{l}\text { Irrad: } \\
\text { Temp.., }{ }^{\circ} \mathrm{C}\end{array}$ & $\begin{array}{l}\text { Fluence, } \\
\mathrm{n} / \mathrm{cm}^{2}(\dot{E}>0.1)\end{array}$ & $\begin{array}{c}\text { Stress, } \\
\text { Initial } \\
\end{array}$ & $\begin{array}{l}\text { MPa } \\
\text { Final }\end{array}$ & $\begin{array}{l}\text { Final } \mathrm{S} \\
\text { Elastic }\end{array}$ & $\begin{array}{l}\text { ain, } \% \\
\text { Creep } \\
\end{array}$ & Total \\
\hline 15 & 412 & $7.6 \times 10^{22}$ & 328 & 151 & 0.09 & 2.3 & 2.4 \\
\hline 13 & 423 & $7.8 \times 10^{22}$ & 159 & 143 & 0.09 & 1.2 & 1.3 \\
\hline 6 & 458 & $11.2 \times 10^{22}$ & 85 & 81 & 0.05 & 1.2 & 1.2 \\
\hline 8 & 444 & $13.0 \times 10^{22}$ & 237 & 59 & 0.04 & 3.6 & 3.6 \\
\hline 12 & 420 & $14.9 \times 10^{22}$ & 82 & 72 & 0.04 & 1.3 & 1.4 \\
\hline
\end{tabular}

After removing the sodium from the specimen train, duplicate samples of each beam were cut astride the peak-curvature centerline of the beam, as shown in Figure 1, step 1 . The samples were roughly 3/16-inch in width, 0.030 -inch thick, and as long as the individual beams were wide. (This dimension varied from 0.17 inch in Beam 8 to 0.30 inch in Beam 12). Extreme care was exercised throughout the sample extraction procedure to minimize any extraneous stresses on the beams.

After extraction from the beam train, the samples were removed from the hot cell for the preparation of discs for TEM. The sequence of events followed in this phase of sample preparation is illustrated in steps 2 through 5, Figure 1. In step 2, the sodium-exposed surfaces (both concave and convex surfaces) were lightly buffed with 400-grit metallographic paper to remove scale and oxide films that have been found to interfere with subsequent electro-discharge machining and electropolishing. The buffed surfaces were then electropolished lightly to remove the superficial cold-worked layer produced by buffing. This procedure removed, on the average, approximately 0.001 -inch of surface. In step 3, one of the tivo samples from each beam was sliced through its thickness with an 0.006 -inch thick diamond-impregnated cutoff wheel to isolate the tension region from the compression region of the beam and to provide a more optimum foil thickness for single-jet electropolishing. While maintaining strict identification of surfaces and stress states, duplicate 3-mm diameter discs were cut by electrodischarge machining from each of the two slices, as shown in step 4. These discs were then perforated from the sliced surface by single-jet electropolishing to provide thin foils of the tension and compression regions of each beam at a depth from the original surface not substantially greater than the 0.001 -inch depth removed in step 2 . 

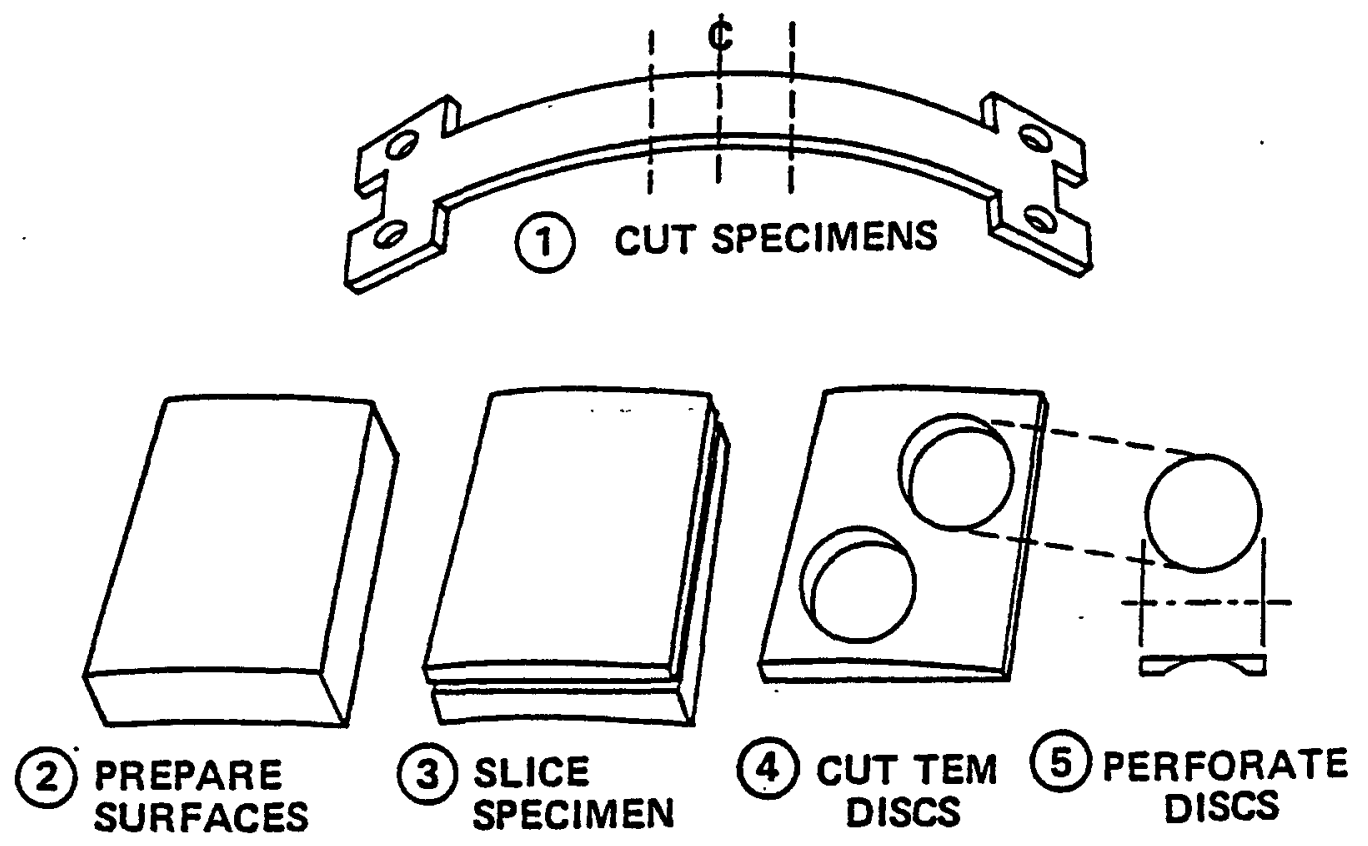

FIGURE 1. Sequence of Operations Followed in the Preparation of the TEM Foils of CI Uniform Beam Specimens.

Foils of the neutral axis of the beams were prepared by twin-jet electropolishing of discs cut from the unsliced specimen of each beam. Since the polishing rates of the two jets in a twin-jet electropolisher are rarely the same, electropolishing was interrupted at measured intervals during preparation of the neutral axis foils to rotate the discs $180^{\circ}$ in the polishing apparatus. This assured that the perforation occurred as close to the true centerline (i.e., the neutral axis) as possible. All electropolishing was performed with a Fischione twin-jet electropolisher; the electroiyte was a solution of 20 percent perchloric acid in ethanol maintained at $-40^{\circ} \mathrm{C}$. The foils were examined in a JEM-6A electron microscope operated at $100 \mathrm{kV}$.

\subsubsection{Results and Discussion}

Void images representative of the tension, compression and neutral regions of Beams 6,8 and 12 are shown in Figures 2, 3 and 4 respectively. The three beams were extracted from the cl creep assembly after the eighth and final discharge of the assembly from EBR-II. Although the in-reactor residence time of all beams was the same, the irradiation history of each is unique as the result of their different axial locations in the core. The differences in irradiation parameters (see Table 1 for details) are readily apparent when one compares the void images of the three beams. (To permit a one-to-one comparison of the three sets of images, plates with the same magnification and representing foils of similar thickness were selected for the figures.) Aside from the striking differences between the void distribution of Beam 6 and those of beams 8 and 12, the most significant observations one can make without benefit of quantitative void image analysis are that (1) a sharp difference in void density exists between stressed and unstressed regions and (2) there appears to be little difference in void density between tension and compression regions of the beams.

To more clearly demonstrate the effect of as much as a factor of two increase in fluence, these images can be compared with those collected from beams 13 and 15 (Figure 5) after their removal from the test assembly at the conclusion of interim examination No. 5. The sharp increases in both void size and void density are readily apparent. 
6., ,
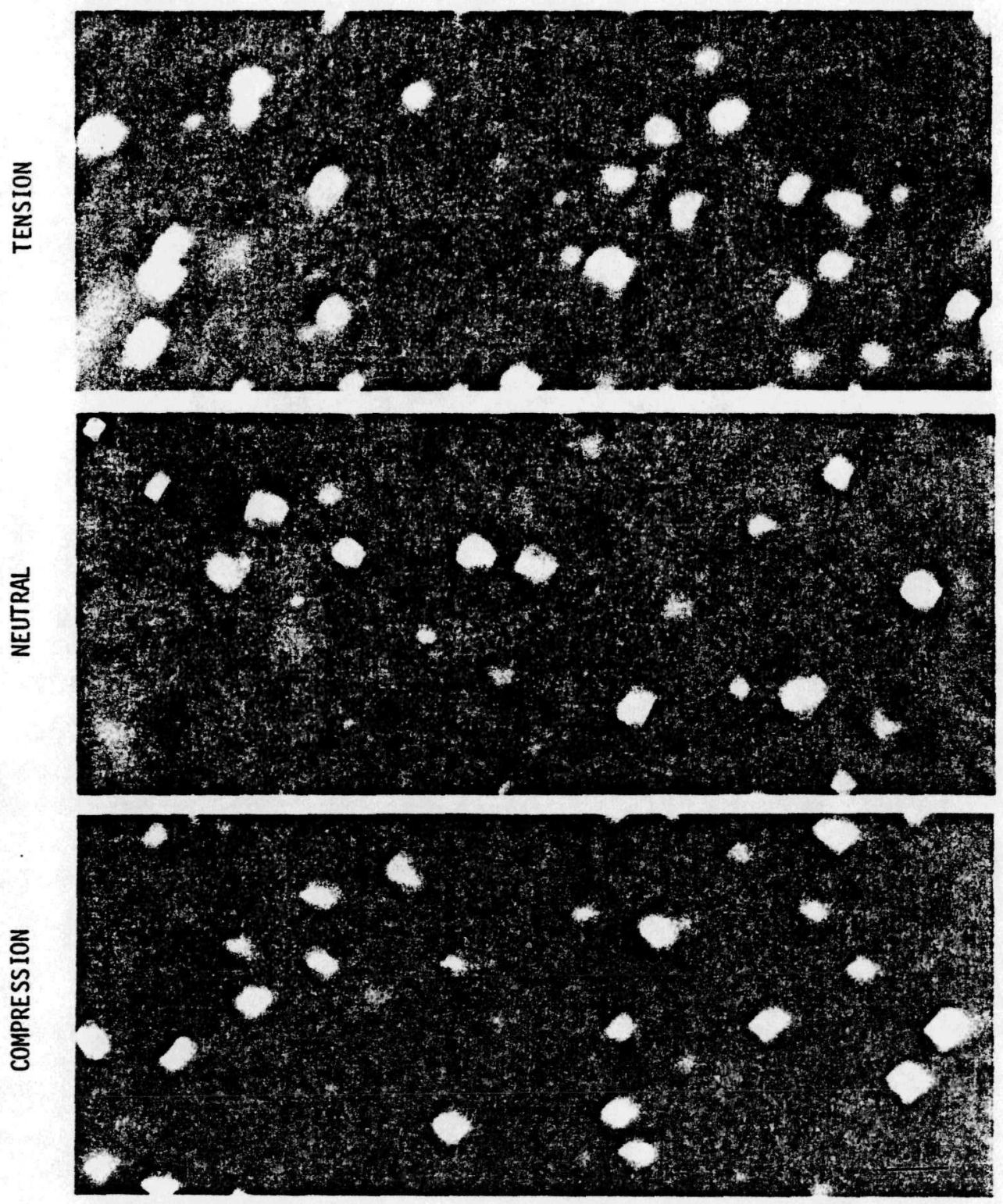

FIGURE 2. Void Images Representative of the Tension Side, the Neutral Axis and the Compression Side of AISI 316-CW Bent Beam Specimen 6 . Beam 6 was irradiated at $450^{\circ} \mathrm{C}$ to $11.2 \times 10^{22} \mathrm{n} / \mathrm{cm}^{2}$ ( $E>0.1 \mathrm{MeV}$ ) and sustained a total strain of 1.2 percent.

At least six regions of each foil were examined in detail and analyzed for void size, void density and percent void swelling. Weighted averages of the three types of data are summarized in Table 2 for the three beams examined in this program and the two low fluence beams examined earlier. The results show a clear effect of stress on swelling in the two highest fluence specimens, beams 8 and 12, with swelling levels in the tension and compression regions about a factor of two higher than in the unstressed central zone of the beams. These results corroborate the findings on Beam 13, as previous ly reported [9]. In the latter work, we proposed that the increase in swelling with stress was due to an accelerated void nucleation in the stressed material, as the data on both beams 12 and 13 seem to indicate. However, this explanation does not fit the trends shown by Beam 8 whose void densities are relatively uniform throughout the thickness of the beam, but whose void sizes are not only substantially higher than Beam 12 but show a sizeable increase in the stressed regions relative to that of the central unstressed zone. These increases in void sizes do not appear to reflect the slightly higher irradiation temperature, since Beam 6 , with an even higher temperature exhibits void sizes comparable to those of Beam 12. Moreover, if this increase were a purely thermal effect, one would expect to see a corresponding increase in void size of the unstressed material. This clearly was not the case. Thus, the data seem to indicate that the stressenhanced swelling observed in Beam 8 is the result of accelerated void growth rather than accelerated void nucleation as the Beam 12 and earlier data had indicated. 


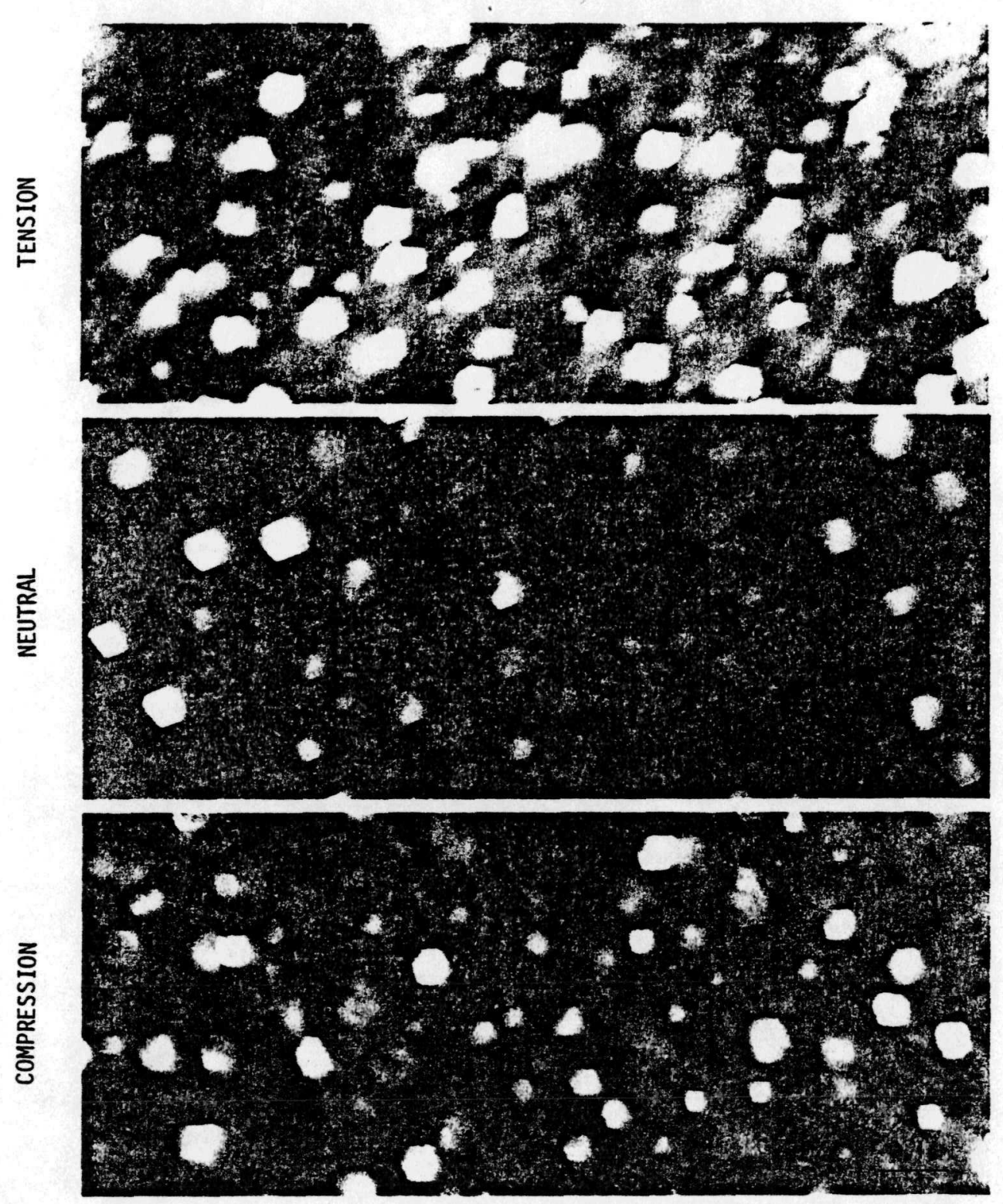

FIGURE 3. Void Images Representative of the Tension Side, the Neutral Axis and the Compression Side of AISI 316-CW Bent Beam Specimen 8. Beam 8 was irradiated at $444^{\circ} \mathrm{C}$ to $13.0 \times 10^{22} \mathrm{n} / \mathrm{cm}^{2}$

$(E>0.1 \mathrm{MeV})$ and sustained a total strain of 3.6 percent.

Except for a slightly higher fluence level in Beam 12 and a 24-degree higher temperature in Beam 8, the only significant difference between the two beams is their stress-strain histories. Beam 8 was originally loaded to a peak fiber stress of $237 \mathrm{MPa}$; the load on Beam 12 was $82 \mathrm{MPa}$. By the end of the irradiation, these stresses were reduced to 59 and $72 \mathrm{MPa}$, respectively, but the total strain accumulated by Beam 8 was more than twice that of Beam 12. These differences in stress-strain histories are clearly illustrated in Figure 6 . Thus, the Beam 8 data showing accelerated void growth and the Beam 12 data showing accelerated void nucleation as a function of stress suggest that the mechanism for stress-enhanced swelling, although independent of the sign of the applied stress, may be a sensitive function of the magnitude of that stress.

\subsection{References}

1. F. A. Garner, E. R. Gilbert and D. L. Porter, "Stress-Enhanced Swelling of Metals During Irradiation," Proc. ASTM 10th International Symposium on Effects of Radiation on Materials, ASTM STP 725, Savannah, GA, June 3-5, 1980, 680-697.

2. F. A. Garner, "The Microchemical Evolution of Irradiated Stainless Steels," HEDL-SA-2159, Proceedings of AIME Symposium on Irradiation Phase Stability, October 5-9, 1980, Pittsburgh, PA, 165-189. 

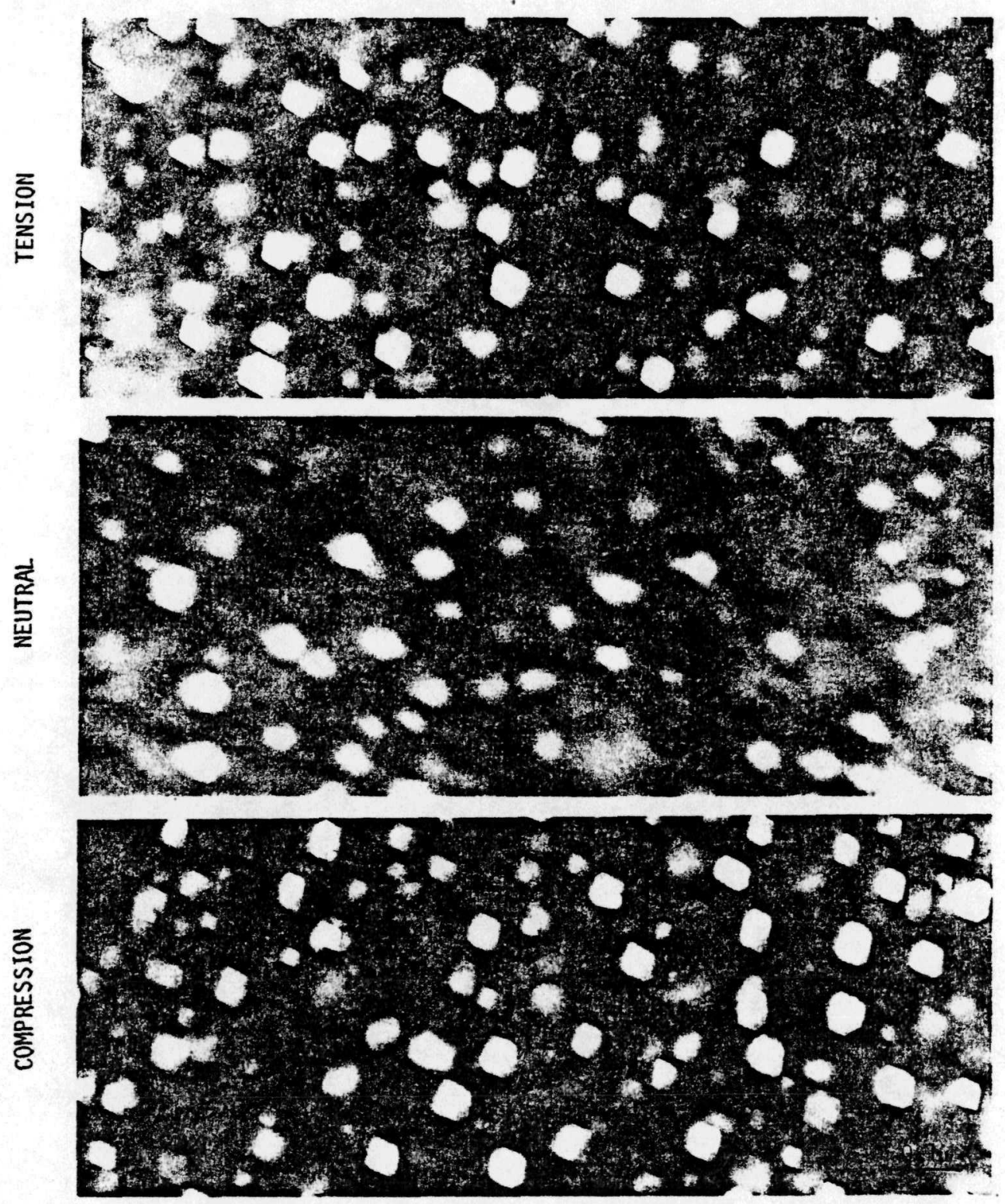

FIGURE 4. Void Images Representative of the Tension Side, the Neutral Axis and the Compression Side of AISI 316-CW Bent Beam Specimen 12. Beam 12 was irradiated at $420^{\circ} \mathrm{C}$ to $14.9 \times 10^{22} \mathrm{n} / \mathrm{cm}^{2}$ $(E>0.1 \mathrm{MeV})$ and sustained a total strain of 1.4 percent.

3. F. A. Garner, "Extrapolation of Stress-Affected Swelling Models Into Compressive and Cyclic Stress States," DAFS Quarterly Progress Report, DOE/ER-0046/5, 198-218.

4. F. A. Garner and D. L. Porter, "History Dependence and Consequences of the Microchemical Evolution of AISI 316," Effects of Radiation on Materials: Eleventh Conference, ASTM STP 782, H. R. Brager and J. S. Perrin, Eds., 1982, 295-309.

5. R. J. Puigh, A. J. Lovell and F. A. Garner, J. Nucl. Mater. $122 \& 123$ (1984), pp. 242-245.

6. K. C. Russell and F. A. Garner, "The Effect of Applied Stress on Precipitate Stability in Irradiated AISI 316," DAFS Quarterly Progress Report, DOE/ER-0046/7, 180-197.

7. S. K. Khera, C. Schwaiger and H. U1lmaier, J. Nucl. Mater. 92, 299-305, 1980.

8. P. Jung and H. K. Sahu, "Void Swelling and Irradiation Creep in Stainless Steel Under Compressive and Tens.ile Stress," presented at the First International Conference on Fusion Reactor Materials, Tokyo, Dec. 3-6, 1984 . 


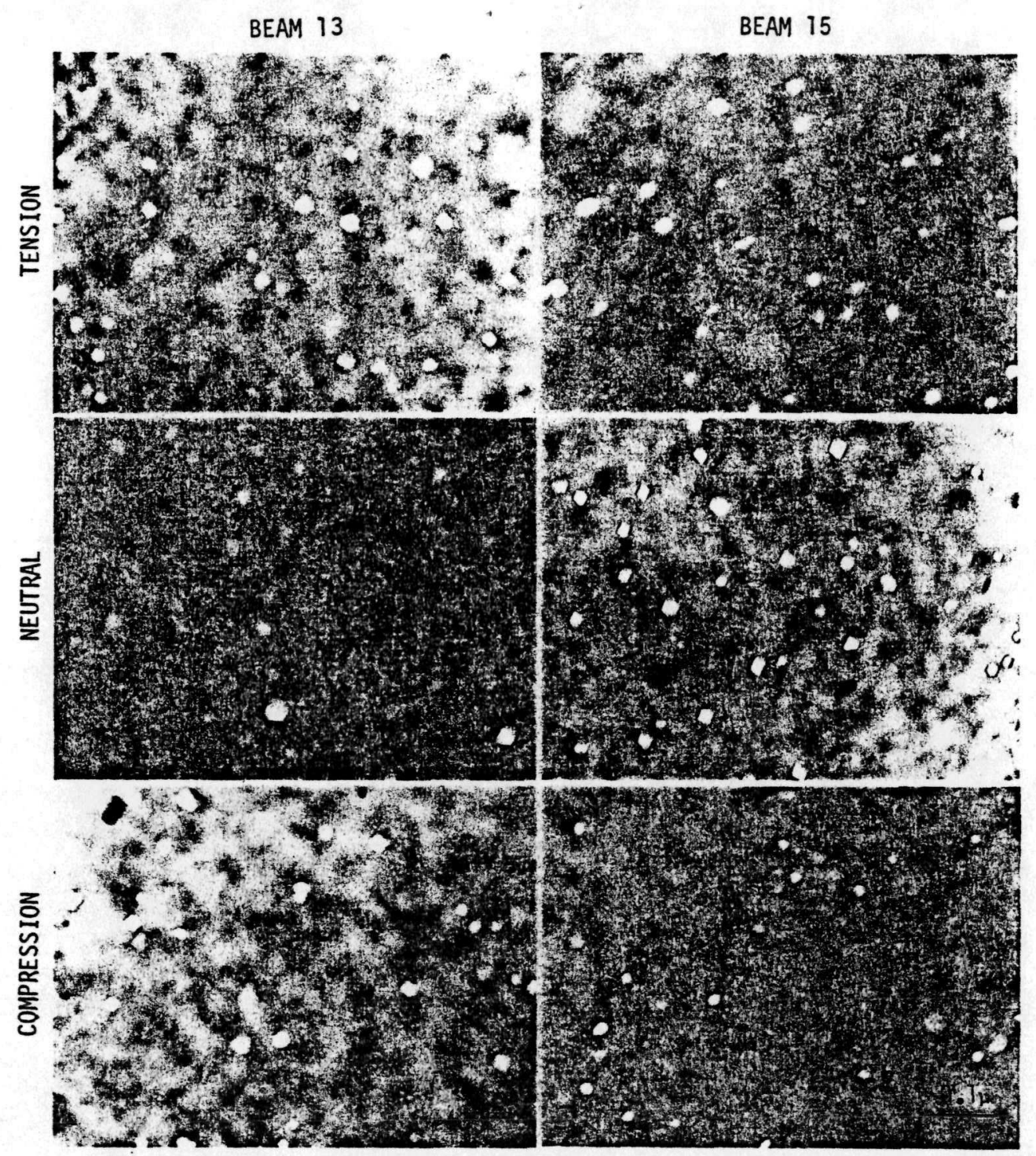

FIGURE 5. Void Images Representative of the Tension Side, the Neutral Axis and the Compression Side of AISI 316-CW Bent Beam Specimens 13 and 15. Beam 13 was irradiated at $423^{\circ} \mathrm{C}$ to $7.8 \times 10^{22}$ $\mathrm{n} / \mathrm{cm}^{2}(\mathrm{E}>0.1 \mathrm{MeV}$ ) and sustained a total strain of 1.3 percent; Beam 15 was irradiated at $412^{\circ} \mathrm{C}$ to $7.6 \times 10^{22} \mathrm{n} / \mathrm{cm}^{2}$ and sustained a total strain of 2.4 percent.

9. T. Lauritzen, W. L. Bell, J. M. Rosa and S. Vaidyanathan, "Some Observations on the Effect of Stress on Irradiation-Induced Swelling in AISI 316, "Effects of Radiation on Materials, 12th Conference,

F. A. Garner and J. S. Perrin, Eds., American Society for Testing and Materials, 1984, in publication.

\subsection{Future Work}

These and other recent data on the stress-affected development of radiation-induced microstructure are being compiled prior to an extensive reanalysis of the models employed in creep and stress-affected swelling.

\subsection{Publications}

None. 
TABLE 2

Void Swelling Data: Effect of Stress on Swelling in 20 Percent Cold Worked AISI 316

\begin{tabular}{|c|c|c|c|c|c|c|}
\hline $\begin{array}{l}\text { BEAM } \\
\text { NO. }\end{array}$ & $\begin{array}{c}\text { FLUENCE } \\
n / \mathrm{cm}^{2}(E>0.1)\end{array}$ & $\begin{array}{l}\text { IRRAD. } \\
\text { TEMP., }{ }^{\circ} \mathrm{C}\end{array}$ & $\begin{array}{l}\text { STRESS } \\
\text { STATE }\end{array}$ & VOID DIA., A & $\begin{array}{c}\text { AVERAGE SWELLINC } \\
\text { VOID DENSITY } C^{\prime} \pi^{3} \\
\end{array}$ & $\begin{array}{l}\text { PARAMETERS } \\
\text { SWELLING, } \%\end{array}$ \\
\hline 12 & $14.9 \times 10^{22}$ & 420 & TENSION & 350 & $1.61 \times 10^{15}$ & 3.6 \\
\hline 12 & $14.9 \times 10^{22}$ & 420 & NEUTRAL & 359 & $0.86 \times 10^{15}$ & 2.1 \\
\hline 12 & $14.9 \times 10^{22}$ & 420 & COMPRESSION & 372 & $1.38 \times 10^{15}$ & 3.7 \\
\hline 8 & $13.0 \times 10^{22}$ & 444 & TENSION & 432 & $0.84 \times 10^{15}$ & 3.5 \\
\hline 8 & $13.0 \times 10^{22}$ & 444 & NEUTRAL & 342 & $0.71 \times 10^{15}$ & 1.6 \\
\hline 8 & $13.0 \times 10^{22}$ & 444 & COMPRESSION & 423 & $0.74 \times 10^{15}$ & 3.1 \\
\hline 6 & $11.2 \times 10^{22}$ & 458 & TENSION & 360 & $0.35 \times 10^{15}$ & 0.9 \\
\hline 6 & $11.2 \times 10^{22}$ & 458 & NEUTRAL & 383 & $0.29 \times 10^{15}$ & 0.9 \\
\hline 6 & $11.2 \times 10^{22}$ & 458 & COMPRESSION & 364 & $0.35 \times 10^{15}$ & 1.1 \\
\hline 13 & $7.8 \times 10^{22}$ & 423 & TENSION & 215 & $0.71 \times 10^{15}$ & 0.4 \\
\hline 13 & $7.8 \times 10^{22}$ & 423 & NEUTRAL & 211 & $0.40 \times 10^{15}$ & 0.2 \\
\hline 13 & $7.8 \times 10^{22}$ & 423 & COMPRESSION & 191 & $0.83 \times 10^{15}$ & 0.3 \\
\hline 15 & $7.6 \times 10^{22}$ & 412 & TENSION & 190 & $0.67 \times 10^{15}$ & 0.2 \\
\hline 15 & $7.6 \times 10^{22}$ & 412 & NEUTRAL & 171 & $\quad 0.72 \times 10^{15}$ & 0.2 \\
\hline 15 & $7.6 \times 10^{22}$ & 412 & COMPRESSION & 182 & $0.64 \times 10^{15}$ & 0.2 \\
\hline
\end{tabular}

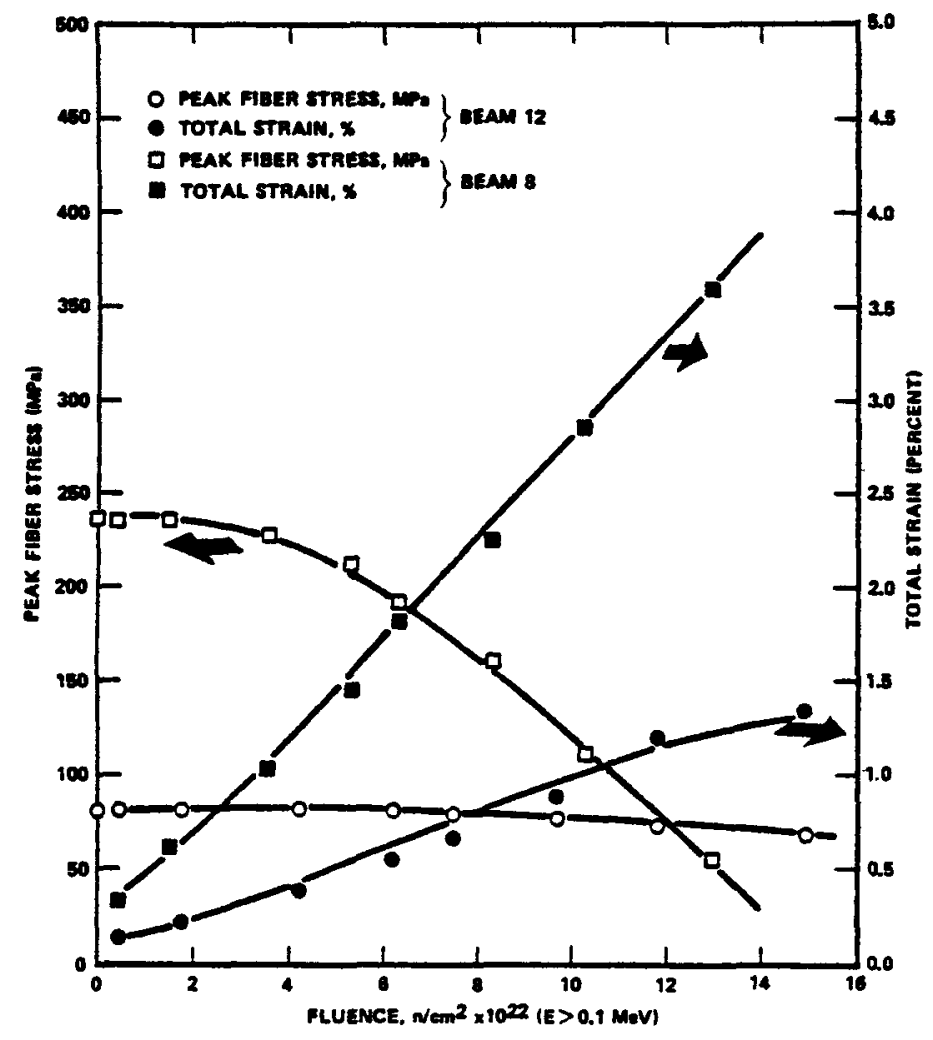

FIGURE 6. Stress-strain Histories of Irradiated AISI 316-CW Bent Beam Specimens 8 and 12. 